OCE Malnutrition Matters, Joint BAPEN and Nutrition Society Meeting, 4-5 November 2008, Harrogate

\title{
The acute impact of treatment on nutritional status in a group of patients with head and neck cancer with a prophylactic feeding tube in situ
}

\author{
M. McLees, P. Cummins and M. Thomson \\ NHS Fife Nutrition and Dietetic Department, Pentland House, Lynebank Hospital, Halbeath Road, Dunfermline, \\ Fife KY11 4UW, UK
}

There have been a plethora of studies indicating that multi-modality treatment for patients with head and neck cancer can often lead to a marked deterioration in their nutritional status. This factor can ultimately have a compounding impact on their clinical outcome ${ }^{(1,2)}$. Furthermore, such treatments can lead to as many as $70 \%$ of patients incurring further weight loss of $\geq 5 \%$ from the pretreatment weight ${ }^{(3)}$. Early nutritional intervention and ongoing nutritional support is therefore regarded as an important component in treatment outcome and quality of life for this patient group. This factor mandates intense dietetic input that aims to minimise nutritional decline throughout treatment. The aim of the present study was to review the acute impact on nutritional status during treatment in a group of patients with head and neck cancer for whom intense dietetic input is required.

A retrospective study was carried out for twenty randomly-selected patients with head and neck cancer who had a prophylactic feeding tube sited. Demographic details were collated for all patients, together with their tumour staging. Nutritional variables included BMI status and percentage weight loss and these nutritional indicators were reviewed at four intervals throughout treatment: on referral to the dietitian; first week treatment (1st wk tt); last week treatment (last wk tt); 1 month post treatment ( 1 mth post-tt). All patients were treated with curative intent and had a prophylactic gastrostomy tube sited as part of their treatment plan. There were fourteen males and six females, with a median age of 64 (interquartile range (IQR) 59-69) years. The majority of patients recruited to the study presented with either a T1 $(15 \%)$ or a T2 $(45 \%)$ staged tumour. The remainder of patients were diagnosed with advanced tumours (T3, 15\%; T4, 25\%).

Table. The effects on BMI $\left(\mathrm{kg} / \mathrm{m}^{2}\right)$ and weight loss during treatment

\begin{tabular}{|c|c|c|c|c|c|c|c|c|}
\hline & \multicolumn{2}{|c|}{ Referral } & \multicolumn{2}{|c|}{$1 \mathrm{st} w \mathrm{ktt}$} & \multicolumn{2}{|c|}{ Last wk tt } & \multicolumn{2}{|c|}{$1 \mathrm{mth}$ post-tt } \\
\hline & Median & IQR & Median & IQR & Median & IQR & Median & IQR \\
\hline $\begin{array}{l}\text { BMI }\left(\mathrm{kg} / \mathrm{m}^{2}\right) \\
\text { Weight loss }(\%)\end{array}$ & 24.5 & $22.4-27$ & $\begin{array}{c}24.1 \\
-1\end{array}$ & $\begin{array}{l}22.5-26.7 \\
-2.5-0\end{array}$ & $\begin{array}{l}23.5 \\
-5\end{array}$ & $\begin{array}{l}22.5-26 \\
-7.1 \text { to }-2.2\end{array}$ & $\begin{array}{l}23.6 \\
-6\end{array}$ & $\begin{array}{l}22.1-25.7 \\
-8.7 \text { to }-2.9\end{array}$ \\
\hline
\end{tabular}

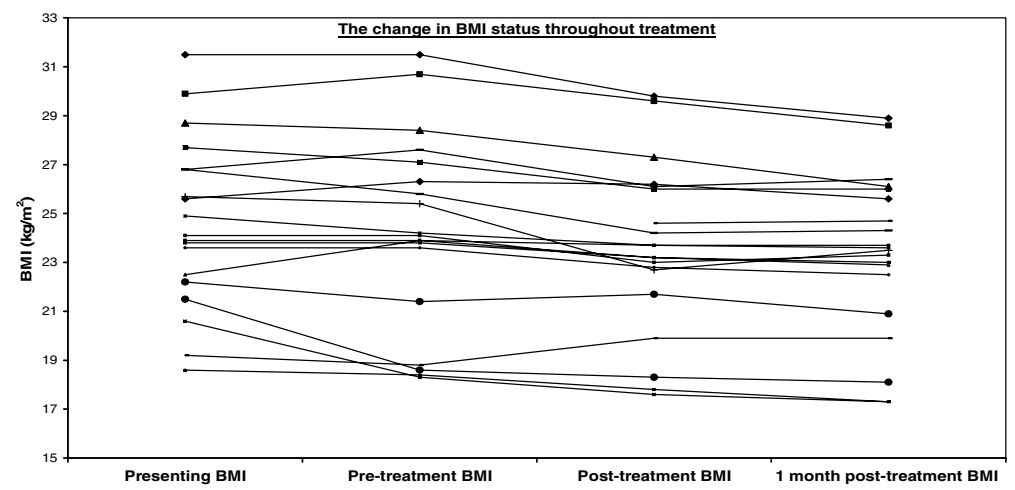

Figure. The impact on BMI $\left(\mathrm{kg} / \mathrm{m}^{2}\right)$ status throughout treatment for each patient.

The present study focused on the acute impact of multi-modality treatment on nutritional status following prophylactic gastrostomy insertion. Evidence indicates that this patient group will incur some weight loss; therefore, the main aim of dietetic intervention on referral to the dietitian was to minimise weight loss during treatment. It is evident that there was minimal impact on BMI and percentage weight loss $\left(-0.4 \mathrm{~kg} / \mathrm{m}^{2}\right.$ and -1 respectively) from referral to the dietitian to $1 \mathrm{st}$ wk $\mathrm{tt}$ (Table). As expected there was a greater reduction in BMI and percentage weight loss between the $1 \mathrm{st} w \mathrm{k} t \mathrm{t}$ and last wk tt $\left(-0.6 \mathrm{~kg} / \mathrm{m}^{2}\right.$ and -3.7 respectively). This result is comparable with those of recent studies between these treatment points ${ }^{(4,5)}$ and, overall, the percentage weight loss incurred was not clinically significant ${ }^{(6)}$. Both BMI (Figure) and percentage weight loss plateaued from last wk tt to $1 \mathrm{mth}$ post tt.

As anticipated, the largest impact on nutritional status observed in the current study was during treatment, but this effect was not clinically significant; it is probably due to prophylactic gastrostomy placement before commencement of treatment, together with established nutritional care pathways and intense dietetic input.

1. Capra S, Ferguson M \& Ried K (2001) Nutrition 17, 769-772.

2. Isenring EA, Capra S \& Bauer JD (2004) Br J Cancer 91, 447-452.

3. Lee JH, Machtay M, Unger LD et al. (1998) Arch Otolaryngol Head Neck Surg 124, 871-875.

4. Wiggenraad RGJ, Flierman L, Goossens A et al. (2007) Clin Otolaryngol 32, 384-390.

5. Mackenzie L (2007) Audit of Home Enteral Tube Fed Patients with Head and Neck Cancer Discharged from the Edinburgh Cancer Centre in 2005 and 2006. Edinburgh: Lothian University Hospital Trust.

6. Todorovic V \& Micklewright A (editors) (2004) A Pocket Guide to Clinical Nutrition, 3rd ed. Redditch, Worcs.: PEN Group Publications. 